\title{
Progesterone supplementation extends uterine receptivity for blastocyst implantation in mice
}

\author{
Haengseok Song ${ }^{1,3}$ Kyuyong Han $^{2,4}$ and Hyunjung Lim²,4 \\ ${ }^{1}$ Departments of Pathology and Immunology, ${ }^{2}$ Obstetrics and Gynecology, Washington University School of \\ Medicine, 4566 Scott Avenue, St Louis, Missouri 63110, USA, ${ }^{3}$ Laboratory of Reproductive Biology and Infertility, \\ Sungkyunkwan University School of Medicine, Cheil General Hospital and Women's Healthcare Center, 1-19, \\ Mukjeong-dong, Jung-gu, Seoul 100-380, South Korea and ${ }^{4}$ Department of Biomedical Science and Technology, \\ Institute of Biomedical Science and Technology, Konkuk University, 1 Hwayang-dong, Kwangjin-gu, Seoul 143-701, \\ South Korea
}

Correspondence should be addressed to H Lim, Department of Biomedical Science and Technology, Institute of Biomedical Science and Technology, Konkuk University, 1 Hwayang-dong, Kwangjin-gu, Seoul 143-701, South Korea; Email: hlim@konkuk.ac.kr

\begin{abstract}
We previously showed that blastocyst can initiate implantation beyond the normal 'window' of uterine receptivity on day 5 of pregnancy and pseudopregnancy (PSP) in mice. In this study, we investigated whether uterine receptivity for blastocyst implantation can be further extended on day 6 of PSP and the role of progesterone $\left(P_{4}\right)$ on this event. Embryo transfers, experimentally induced decidualization, in situ hybridization and $\left[{ }^{3} \mathrm{H}\right]$ thymidine incorporation were performed. Blastocysts initiate attachment reaction within $48 \mathrm{~h}$ when transferred on day 5, but not on day 6 of PSP. Likewise, decidualization reaction occurred on days 4 and 5 of PSP, but completely failed on day 6 . However, $P_{4}$ supplementation partially retains uterine receptivity for blastocyst implantation and decidualization on day 6 of PSP. In addition, certain indicators of uterine receptivity, such as cell proliferation profile and expression patterns of implantation-related genes were similarly observed on days 4 and 5 of PSP, but not on day 6. Consistent with embryo transfer and decidualization, exogenous administration of $\mathrm{P}_{\mathbf{4}}$ partially restores these indicators on day 6 of PSP. We concluded that critical physiological changes occur between days 4 and 5 of PSP, leading to uterine nonreceptivity on day 6 , but $P_{\mathbf{4}}$ is able to extend the uterine receptivity through day 6 .
\end{abstract}

Reproduction (2007) 133 487-493

\section{Introduction}

Uterine milieu for blastocyst implantation is classified into prereceptive, receptive, and non-receptive phases. Uterine receptivity is defined as the window of limited time, when the uterine environment is conducive to support blastocyst growth, attachment reaction, and subsequent events of implantation (Psychoyos 1973, Paria et al. 1993, Dey 1996). Extensive embryo transfer experiments were performed on various days of pseudopregnancy (PSP), and the first sign of attachment reaction in the implantation process, the increased vascular permeability, was examined $24 \mathrm{~h}$ after embryo transfer to understand uterine receptivity in mice. These experiments suggested that blastocyst can implant only for a limited period on day 4 of pregnancy or PSP. The establishment of uterine receptivity for blastocyst implantation in rodents depends on an appropriate combination of $\mathrm{P}_{4}$ and estrogen, but the molecular events by which estrogen converts the $\mathrm{P}_{4}$-primed uterus to the receptive state, activates the blastocyst, and initiates the implantation process remain ill-defined.

We have previously shown that the 'window' of uterine receptivity for blastocyst implantation in mice remains open for an extended period at lower estrogen $\left(\mathrm{E}_{2}\right)$ levels (3 ng) but rapidly closes at higher levels (Ma et al. 2003). Rapid closure of uterine receptivity at high $E_{2}$ levels is accompanied by aberrant expression of implantation-related genes. These results demonstrate that optimal levels of ovarian steroids are critical in regulating molecular mechanisms for uterine receptivity in mice. This study utilized delayed implantation model where recipient mice for embryo transfer were ovariectomized and treated with exogenous hormones to monitor implantation rates under various experimental conditions. Thus, one question remains to be answered is whether the 'window' of uterine receptivity can be extended in mice with or without hormonal manipulation. 
Cytosolic phospholipase $\mathrm{A}_{2}\left(\mathrm{CPLA}_{2}\right)$ is a fatty acid liberating enzyme which sits upstream of cyclooxygenases in prostaglandin (PG) biosynthetic pathway (Murakami et al. 2000). Consistent with critical roles of PGs in implantation and decidualization (Lim et al. 1997), CPLA ${ }_{2}$-deficient female mice also exhibit uterine defects (Song et al. 2002). During analysis of implantation phenotypes in these mice, we found that blastocysts which failed to initiate the attachment reaction during the expected time show implantation one day later on day 6 of pregnancy (Song et al. 2002). This suggested that blastocysts require longer time to initiate the implantation process under the condition of sub-optimal uterine receptivity such as uteri deficient of $\mathrm{CPLA}_{2}$ with lower levels of PGs at the time of implantation. Further investigation with extensive embryo transfers using normal recipients on day 5 of PSP demonstrated that blastocyst can initiate the implantation process in conventionally referred nonreceptive uterus (Song et al. 2002).

These findings led us to revisit the definition of 'window' of implantation with extensive embryo transfer on extended days of PSP and investigate the role of progesterone in retaining uterine receptivity in mice. We show here that blastocyst can implant on day 5, but not on day 6 of PSP and that $\mathrm{P}_{4}$ supplementation partially extends uterine receptivity for blastocyst implantation on day 6 of PSP possibly by conditioning uterine environment for implantation via modulation of uterine cell proliferation and expression of some implantationrelated genes.

\section{Materials and Methods}

\section{Mice}

Adult female mice were mated with fertile or vasectomized males of the same strain to induce pregnancy or PSP respectively. The morning of finding a vaginal plug was designated day 1 of pregnancy. Implantation sites (IS) on days 5, 6, or 7 were visualized by i.v. injection $(0.1 \mathrm{ml} /$ mouse) of $1 \%$ Chicago Blue dye solution in saline (Paria et al. 1993). Mice were housed in the semibarrier animal care facility according to $\mathrm{NIH}$ and institutional guidelines for laboratory animals.

\section{Blastocyst transfer to pseudopregnant mice}

Day 4 blastocysts were transferred to the uteri of recipients in the morning $(1000 \mathrm{~h})$ of various days of PSP. Recipient mice were killed at $0900 \mathrm{~h}$ on designated days of PSP. $\mathrm{P}_{4}$ (Sigma) was supplemented to several groups of days 6 and 7 pseudopregnant mice by daily injection from day 5 to the day when the mice were killed. Time of injection is indicated in Table 1. The number of IS was recorded by i.v. injection $(0.1 \mathrm{ml} /$ mouse $)$ of Chicago Blue dye solution (1\% in saline) $48 \mathrm{~h}$ after embryo transfer. Mice were killed 5 min later and IS were demarcated as discrete blue bands along the uteri.

\section{Experimentally induced decidualization in pseudo- pregnant mice}

To induce artificial decidualization, sesame oil was infused intraluminally in one uterine horn on days $4-6$ of PSP. The contra-lateral horn served as control. Mice were killed 4 days later and uterine weights of the infused and non-infused (control) horns were recorded. Fold increases in uterine weights were used as an index of decidualization. $\mathrm{P}_{4}$ was supplemented to one group of day 6 pseudopregnant mice by daily injection $(0900 \mathrm{~h})$ from day 5 to the day when the mice were killed.

\section{Uterine cell type-specific proliferation in pseudopregnant mice}

To examine whether uterine cell type-specific proliferation is associated with the uterine receptivity, the mice on days $4-6$ of PSP received an injection (i.p.) of [methyl- ${ }^{3} \mathrm{H}$ ] thymidine $(25 \mu \mathrm{Ci} / 0.1 \mathrm{ml}$; PerkinElmer, Boston, MA, USA) in the morning $(0800 \mathrm{~h})$ and were killed $2 \mathrm{~h}$ later. Nuclear uptake of $\left[{ }^{3} \mathrm{H}\right]$ thymidine was detected in uterine sections by autoradiography (Lim et al. 1997).

Table 1 Blastocyst implantation beyond normal 'window' of uterine receptivity in mice.

\begin{tabular}{lcccc}
\hline Days of transfer & No. of recipients & No. of embryos transferred & No. of recipients with IS $(\%)$ & No. of IS $(\%)$ \\
\hline Day 4 & 5 & 60 & $5(100)$ & $6(86)$ \\
Day 5 & 7 & 92 & $0(0)$ & $31(52)$ \\
Day 6 & 8 & 94 & $9(60)$ & $0(48)$ \\
(I) Day 6 $\left(\mathrm{P}_{4}: 0900 \mathrm{~h}\right)$ & 15 & 221 & $0(0)$ & $0(23)$ \\
(II) Day 6 $\left(\mathrm{P}_{4}: 1400 \mathrm{~h}\right)$ & 6 & 69 & $0(0)$ & $0(0)$ \\
(III) Day 7 $\left(\mathrm{P}_{4}: 0900 \mathrm{~h}\right)$ & 7 & 90 & $0(0)$ & $0(0)$ \\
(IV) Day 7 $\left(\mathrm{P}_{4}+\mathrm{E}_{2}: 0900 \mathrm{~h}\right)$ & 7 & 98 & $0(0)$
\end{tabular}

Day 4 blastocysts were transferred into uteri of recipients on various days of pseudopregnancy. $\mathrm{P}_{4}$ supplemented recipients received an injection of $\mathrm{P}_{4}$ ( $2 \mathrm{mg}$ /mouse) on day 5 morning (0900 h: I, III, IV) or afternoon (1400 h: II) and continuous daily $\mathrm{P}_{4}$ on the morning from day 6 until killed to examine IS. IV recipients were injected with $\mathrm{E}_{2}(25 \mathrm{ng} / \mathrm{mouse})$ along with $\mathrm{P}_{4}$ on day $7(0900 \mathrm{~h})$ before embryo transfer. All recipients were killed $48 \mathrm{~h}$ after embryo transfer to examine IS by the blue dye method. Data for embryo transfer performed with day 4 and day 5 pseudopregnant recipients, used as control for other embryo transfers in this table, were previously published (Song et al. 2002). 


\section{In situ hybridization}

In situ hybridization was performed as previously described (Das et al. 1994, Lim et al. 1997, Song et al. 2002). Small pieces of tissues were flash-frozen in liquid Histo-Freeze (Fisher Scientific, St Louis, MO, USA). Frozen sections $(12 \mu \mathrm{m})$ were mounted onto poly-Llysine-coated slides, fixed in cold $4 \%$ paraformaldehyde solution in PBS, acetylated, and hybridized at $45^{\circ} \mathrm{C}$ for $4 \mathrm{~h}$ in hybridization buffer containing the ${ }^{35}$ S-labeled antisense cRNA probes. After hybridization, the sections were incubated with RNase A (RNase A, $20 \mu \mathrm{g} / \mathrm{ml}$ ) at $37^{\circ} \mathrm{C}$ for $20 \mathrm{~min}$. RNase A-resistant hybrids were detected by autoradiography using Kodak NTB-2 liquid emulsion (Eastman Kodak, Rochester, NY, USA). Sections hybridized with sense probes served as negative controls. Sense and antisense ${ }^{35}$ S-labeled RNA probes were generated using the appropriate polymerases.

\section{Results}

\section{Blastocysts can initiate attachment reaction in the non-receptive uterus beyond normal 'window' of uterine receptivity}

Uterine environment at day 5 of PSP was considered nonreceptive (Paria et al. 1993). When blastocysts are transferred to these uteri, IS are generally not visible if examined by $24 \mathrm{~h}$. Recently, we have shown that blastocyst can still implant in the non-receptive uterus on day 5 of pregnancy and PSP beyond normal 'window' of uterine receptivity in mice, but they require longer time to initiate the attachment reaction (Song et al. 2002). This led us to hypothesize that blastocyst may initiate the implantation on extended days of PSP in conventionally non-receptive uterus. To test this hypothesis, we performed embryo transfer experiments to recipients on various days of PSP and examined IS $48 \mathrm{~h}$ later rather than $24 \mathrm{~h}$ by blue dye injection. As previously shown (Song et al. 2002), 48\% of blastocysts implanted in the day 5 pseudopregnant uteri of recipients by $48 \mathrm{~h}$ after transfer. This was comparable to implantation rate of embryo transfers performed on day 4 of PSP (52\%; Table 1). These clearly demonstrated that blastocysts can initiate the implantation process on day 5 of PSP in non-receptive uterus in mice. However, whether blastocyst can implant on later days of PSP in conventional non-receptive uterus still remain unanswered. To examine this, we performed embryo transfers to recipients on days 6 and 7 of PSP. In contrast, to comparable implantation rate of day 5 embryo transfer, blastocysts transferred to recipients on days 6 and 7 of PSP completely failed to implant even $48 \mathrm{~h}$ after embryo transfers (Table 1). These results indicate that day 5 pseudopregnant uterus is able to support attachment reaction but requires longer time (48 vs $24 \mathrm{~h}$ ) to manifest the first sign of attachment reaction, the increased vascular permeability. However, this 'window' to initiate attachment reaction is shut off after day 5 .

\section{Progesterone supplementation retains uterine receptivity for blastocyst implantation on day 6 of PSP}

The observation from embryo transfer experiments suggested that the uterine environment with respect to uterine receptivity for blastocyst implantation significantly changes between days 5 and 6 of PSP. Since it is well established that optimal levels of ovarian steroids are key regulators of uterine receptivity, we hypothesized that levels of progesterone could be a key factor to maintain uterine receptivity for blastocyst implantation. In fact, it was reported that $\mathrm{P}_{4}$ levels are maintained during days 3-5 of PSP and the levels significantly decrease by day 6 (Wakuda et al. 1999). Thus, we investigated whether exogenous ovarian steroids could further extend the receptive state for blastocyst implantation. We injected $\mathrm{P}_{4}(2 \mathrm{mg} / \mathrm{mouse})$ daily $(0900 \mathrm{~h})$ from day 5 of PSP to the day when the recipients were killed and performed embryo transfers on day 6 . Recipients were killed at $48 \mathrm{~h}$ after embryo transfer. Interestingly, 9 of 15 day 6 pseudopregnant recipients $(60 \%)$ with daily $\mathrm{P}_{4}$ supplementation showed IS when examined at $48 \mathrm{~h}$ after embryo transfer (Table 1, I). This suggests that decreased level of $\mathrm{P}_{4}$ is a key factor for the uterus to become non-receptive (day 6$)$. The number $(23 \%)$ of IS visualized by the blue dye method in recipients on day 6 of PSP is lower than those of days 4 and 5 of PSP (52 and $48 \%$ ) respectively, suggesting that $\mathrm{P}_{4}$ supplementation is not able to fully restore uterine receptivity on day 6 . To examine if timing of $\mathrm{P}_{4}$ availability is important, we supplemented $\mathrm{P}_{4}$ in the afternoon $(1400 \mathrm{~h})$ rather than in the morning $(0900 \mathrm{~h})$ on day 5 to the recipient. Surprisingly, all the blastocysts transferred to those recipients failed to initiate the attachment reaction (Table 1, II). This result suggests that timely $\mathrm{P}_{4}$ supplementation is critical to maintain uterine environments for providing a more accessible condition for blastocyst implantation. Hormonal supplementation on day 7 of PSP did not help to improve implantation rate in day 7 PSP recipients (Table 1, III-IV). Collectively, the results suggest that critical changes in uterine physiology occur in the uterus between days 5 and 6 of PSP.

\section{Uterus responds to decidualization stimuli beyond normal 'window' of uterine receptivity}

Above results show that blastocysts are capable of initiating attachment reaction beyond normal 'window' of receptivity under appropriate $\mathrm{P}_{4}$ level as judged by increased vascular permeability at the site of implantation. The attachment reaction is immediately followed by decidual response by stromal cells underlying the luminal epithelial cells contacting the blastocyst. As decidual response is a critical component of successful implantation, we tested whether uteri of pseudopregnant recipients on different days respond to an artificial stimulus to induce decidualization beyond the normal 
'window' of uterine receptivity. We gave an intraluminal oil infusion to recipients on days 4, 5, or 6 of PSP and examined the extent of decidual response 4 days later. Artificially induced decidualization occurred in most of the uteri of days 4 and 5 of PSP (5/6 and 6/8), but not in the uteri of day 6 pf PSP (0/7; Fig. 1). To investigate whether $\mathrm{P}_{4}$ supplementation sustain the uterine responsiveness to a deciduogenic stimulus on day 6 as in the case of the attachment reaction, we gave $\mathrm{P}_{4}$ ( $2 \mathrm{mg} /$ mouse) injections on days 5 and 6 of PSP (0900 h) in this experimental model. As shown in Fig. $1, \mathrm{P}_{4}$ injection improved decidual responses in day 6 pseudopregnant mice (5/17) although fold increases in uterine weight $(7.4 \pm 0.9)$ and percentage of mice with decidualization responses (29\%) were lower than those of days 4 and 5 of PSP $(12.1 \pm 2.0$ and $12.8 \pm 1.2$ fold increases in uterine weight, and 83 and $75 \%$ of mice respectively). These results collectively show that initial attachment reaction and subsequent decidual response to the extent comparable to day 4 pseudopregnant uterus can occur on day 5 of PSP, but not thereafter. In addition, $\mathrm{P}_{4}$ supplementation partially improves the uterine condition on day 6 of PSP to support attachment reaction and decidualization.

\section{Cell proliferation profile is altered in the uterus in non-receptive phase}

In mice, the establishment of the receptive uterus for supporting implantation is regulated by coordinated effects of $\mathrm{P}_{4}$ and $\mathrm{E}_{2}$ on differential cell proliferation and

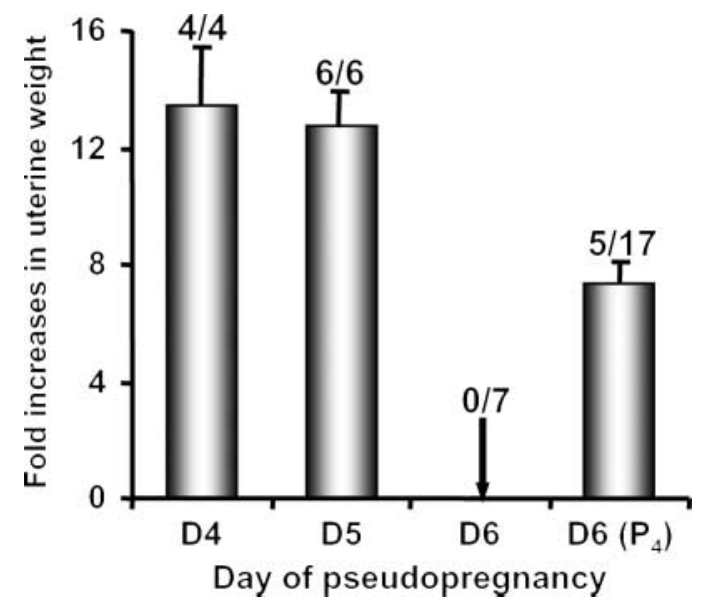

Figure 1 Experimentally induced decidualization in mice on days 4-6 of pseudopregnancy (PSP). Female mice received intraluminal oil infusion on days 4-6 of PSP. A group of day 6 pseudopregnant mice (day $\left.6\left(\mathrm{P}_{4}\right)\right)$ was given with $\mathrm{P}_{4}(2 \mathrm{mg} /$ mouse $)$ by daily injection from day $5(0900 \mathrm{~h})$ to the day when killed. Mice were killed 4 days after oil infusion and uterine weights were recorded. Fold increases denote comparison of weights between infused and non-infused uterine horns. Results of days 4 and 5 of PSP, used as control for decidualization with day 6 of PSP in this experiment, were previously published (Song et al. 2002). The numbers above bars indicate the numbers of responding mice/total mice. Results are mean \pm s.E.M. gene expression (Huet et al. 1989). We suspected that failure of implantation and decidualization on day 6 of PSP is due to uterine delinquency arising from abnormal cell proliferation and/or differentiation. Thus, we compared uterine cell proliferation profiles between days 4 and 6 of PSP by $\left[{ }^{3} \mathrm{H}\right]$ thymidine incorporation (Fig. 2). As previously observed (Huet et al. 1989), proliferation was restricted to stromal cells. However, no difference in proliferation pattern was noted between days 4 and 5 of PSP. However, $\left[{ }^{3} \mathrm{H}\right]$ thymidine incorporation was aberrantly noted in luminal epithelial cells with very low to undetectable levels in the stroma (Fig. 2) in day 6 pseudopregnant mice. In addition, the number of proliferating cells on day 6 of PSP was quite lower than those on days 4 and 5 of PSP. Exogenous supplement of $\mathrm{P}_{4}(2 \mathrm{mg} /$ mouse $)$ on day 5 of PSP $(0900 \mathrm{~h})$ maintained normal uterine cell proliferation profiles in some uteri of day 6 pseudopregnant mice.

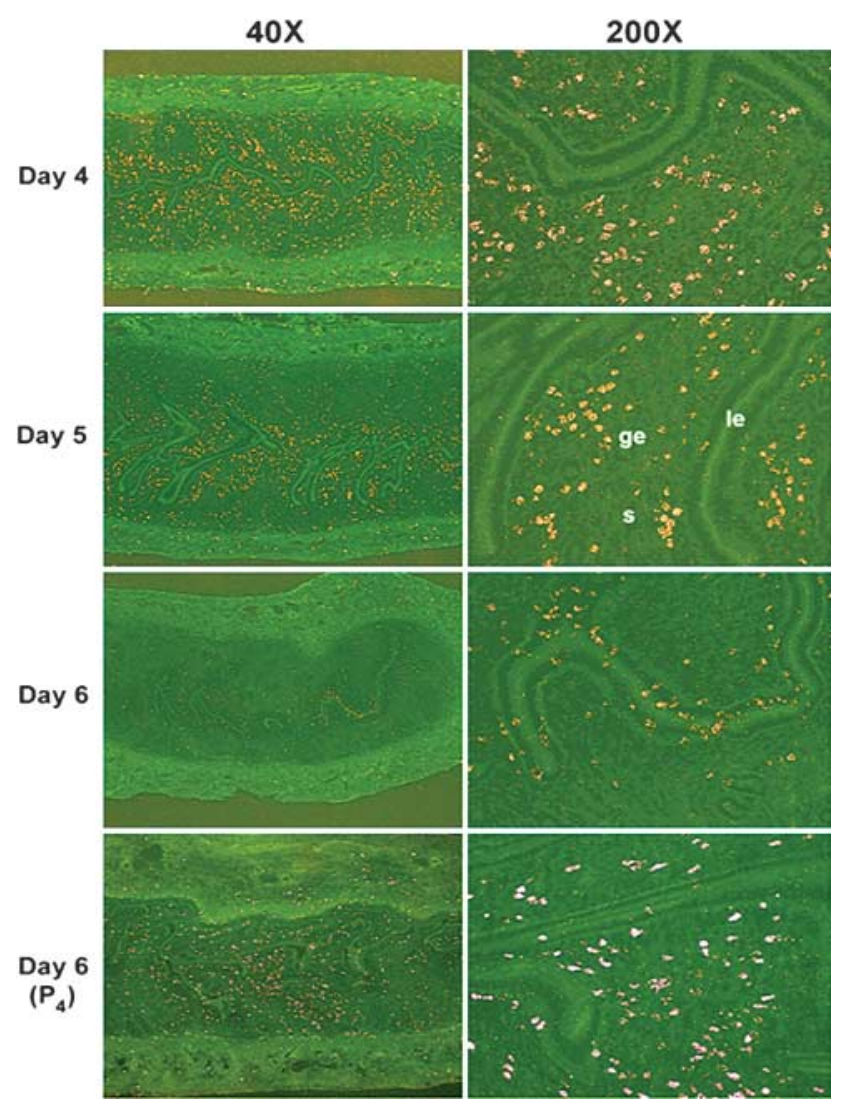

Figure 2 Nuclear incorporation of $\left[{ }^{3} \mathrm{H}\right]$ thymidine in proliferating uterine cells on days $4-6$ of pseudopregnancy (PSP). Mice on days 4-6 of PSP received an injection (i.p.) of $\left[{ }^{3} \mathrm{H}\right]$ thymidine in the morning $(0800 \mathrm{~h})$ and were killed $2 \mathrm{~h}$ later. A group of day 6 pseudopregnant mice (day $6\left(\mathrm{P}_{4}\right)$ ) was given with a single injection of $\mathrm{P}_{4}(2 \mathrm{mg} /$ mouse $)$ on day $5(0900 \mathrm{~h})$. Note nuclear $\left[{ }^{3} \mathrm{H}\right]$ thymidine uptake in epithelial cells on day 6 of PSP, but in stromal cells of uteri of day 6 pseudopregnant mice injected with $\mathrm{P}_{4}$ on day 5. Patterns of $\left[{ }^{3} \mathrm{H}\right]$ thymidine incorporation in various days of PSP were shown under darkfield at $40 \times$ (left panel) and $200 \times$ (right panel) respectively. These experiments were repeated thrice with similar results. 
The result that uteri on day 6 PSP no longer maintain cell proliferation profile of typical $\mathrm{P}_{4}$ dominance suggests that the uterus on this day possibly undergoes critical change in hormonal milieu leading to uterine refractoriness to implantation.

\section{Differential expression of implantation-related genes during changing uterine receptivity}

Plasma levels of $\mathrm{P}_{4}$ during pregnancy or PSP is one principal factor to provide the receptive environment by regulating certain local mediators. Thus, we examined expression of several implantation-related genes, such as COX-1 (Ptgs1), Amphiregulin (Areg), Hoxa10 (Hoxa10), Flk-1(Kdr), and LIF (Lif) using in situ hybridization on days 4-6 of PSP to investigate whether change in hormonal milieu on day 6 of PSP is accompanied by aberrant expression patterns of these genes (Figs 3 and 4). All of these genes are expressed in a cell type-specific manner during implantation (Chakraborty et al. 1995, Das et al. 1995a, Benson et al. 1996, Song et al. 2000). Ptgs1, as reported previously, was expressed mainly in luminal epithelium with modest expression in glandular epithelium on day 4. Interestingly, the accumulation of Ptgs1 mRNA in the luminal epithelium gradually decreased on day 5 and was no longer detected on day 6 , while its expression in the glandular epithelium was intensified on day 6. Areg was expressed in the entire luminal epithelium on day 4, but gradually decreased and became almost undetectable on day 6. However, Hoxa10 and $K d r$ maintained similar expression patterns in the stroma throughout this period. Since Hoxa10 and Areg are both $\mathrm{P}_{4}$-regulated genes, it is interesting to note that only the epithelial expression of Areg, but not the stromal expression of Hoxa10, decreases to undetectable levels on day 6 when blood levels of $\mathrm{P}_{4}$ sharply decrease (Wakuda et al. 1999). Surprisingly, while exogenous $P_{4}$ supplementation partly extends the uterine receptivity for the attachment reaction and decidualization, the expression patterns of Ptgs 1 and Areg on day 6 were not influenced by this treatment.

In contrast to implantation-related genes examined above, $\mathrm{P}_{4}$ supplementation had an effect on the expression of Lif (Fig. 4). Lif, expressed in uterine glands prior to implantation on day 4 of pregnancy (Bhatt et al. 1991, Song et al. 2000), maintained expression in glands on days 4 and 5 of PSP. However, the expression rapidly decreased and became undetectable on day 6 of PSP (Fig. 4). Although it was previously shown that Lif expression is mainly regulated by estrogen (Bhatt et al. 1991, Shen \& Leder 1992), $P_{4}$ supplementation in some day 6 pseudopregnant mice maintained its expression in uterine glands (arrows in the right panel of bottom). Collectively, these results suggest that uterine environment on day 6 of PSP undergoes certain molecular changes that reduce the efficiency of implantation and that $\mathrm{P}_{4}$ is a key factor, even if not a sole one, to retain uterine environment for blastocyst implantation.

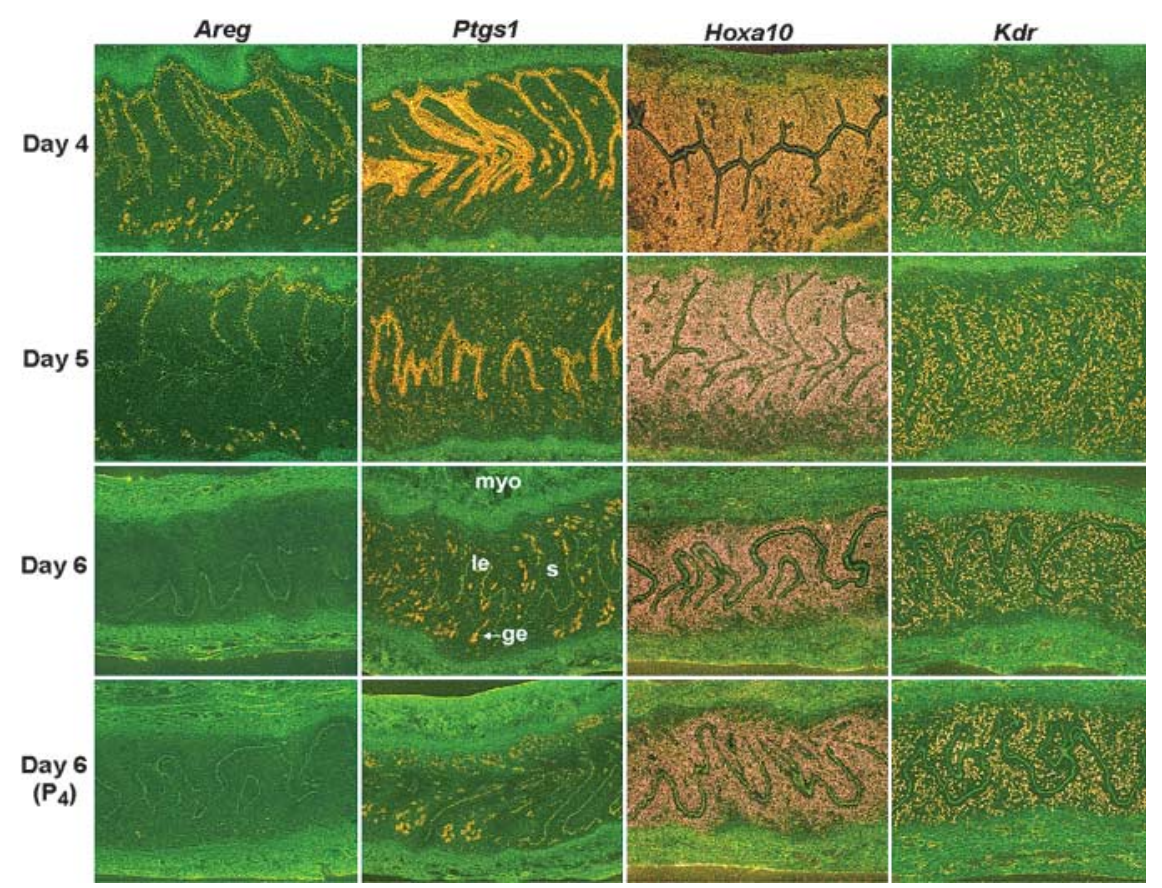

Figure 3 Expression of implantation-related genes in uteri of days 4-6 of pseudopregnant mice. In situ hybridization of Areg, Ptgs1, Hoxa10, Kdr1 mRNAs in uterine sections on days 4-6 of PSP are shown under darkfield at $40 \times$. A group of day 6 pseudopregnant mice $\left(\right.$ day $\left.6\left(P_{4}\right)\right)$ was given with a single injection of $\mathrm{P}_{4}(2 \mathrm{mg} / \mathrm{mouse})$ on day 5 (0900 h). le, Luminal epithelium; ge, glandular epithelium; s, stroma; myo, myometrium. These experiments were repeated twice with similar results. 

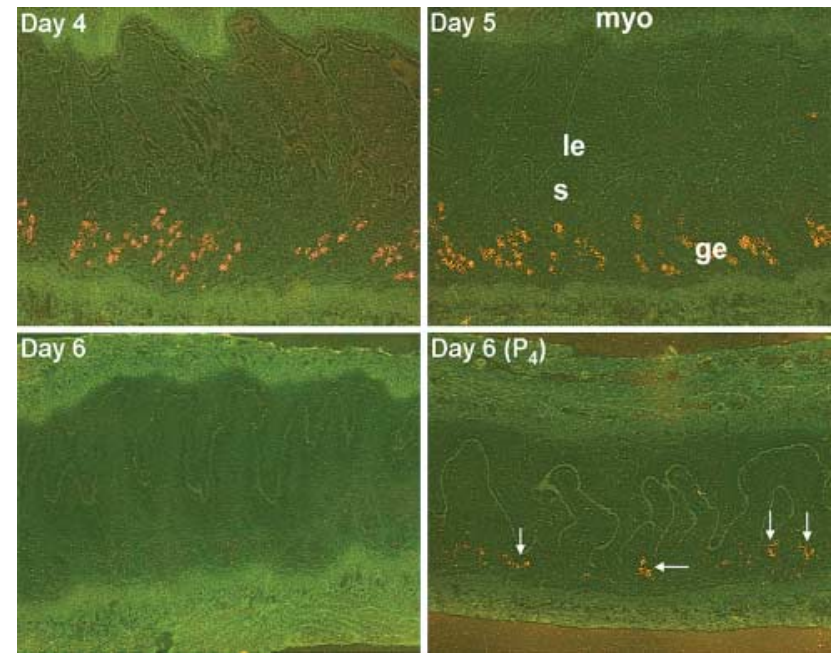

Figure 4 Differential expression of Lif in uteri of days 4-6 of pseudopregnant mice. In situ hybridization of Lif mRNAs is represented under darkfield at $40 \times$. Day $6\left(\mathrm{P}_{4}\right)$ represents the uterus of day 6 pseudopregnant mice with a single injection of $\mathrm{P}_{4}(2 \mathrm{mg} / \mathrm{mouse})$ on day 5 . Arrows indicate the uterine glands that Lif expression is still retained on day 6 of pseudopregnancy. le, Luminal epithelium; ge, glandular epithelium; s, stroma; myo, myometrium. These experiments were repeated thrice with similar results.

\section{Discussion}

Synchronization of embryo development to the blastocyst stage with uterine receptivity is a prerequisite for successful implantation. Indeed, implantation failure due to inappropriate uterine receptivity is one of the major causes of infertility in humans, particularly in the case of embryo transfers following in vitro fertilization (Nikas et al. 1999). However, molecular mechanisms by which the uterus achieves receptive state for blastocyst implantation still remain elusive. The highlight of the present investigation is that blastocysts can initiate attachment reaction on days 5 and 6 (with $\mathrm{P}_{4}$ injection) of PSP, which is beyond the conventional 'window' of uterine receptivity in mice. In addition, decidualization, another aspect of the implantation process, can occur similarly. The finding that day 6 pseudopregnant uteri support attachment reaction only under exogenous $\mathrm{P}_{4}$ supplementation suggests that declining levels of $\mathrm{P}_{4}$ is one critical factor restricting uterine receptivity.

The molecular and cellular events leading to uterine receptivity for blastocyst implantation in mice depend on ovarian steroids (Dey 1996). Various local factors including growth factors, cytokines, transcription factors, and PGs are implicated in molecular events of implantation under the influence of $\mathrm{P}_{4}$ and $\mathrm{E}_{2}$ (Das et al. 1994, 1995a, Benson et al. 1996, Lim et al. 1997b, Song et al. 2000). Our study shows that implantation-related genes of the epithelial compartments are decreased on day 6 of PSP, suggesting that epithelial cells are not conditioned for attachment reaction on this day. $\mathrm{P}_{4}$ supplementation only partially improves gene expression and it is coincident with partial rescue of implantation rate on day 6 of PSP.

Among implantation-specific genes, Lif is considered critical for implantation since $\mathrm{LIF}^{-/-}$mice show implantation and decidualization failures (Stewart et al. 1992, Song et al. 2000). Thus, it is interesting to see that Lif is expressed in uterine glands as long as uterus is receptive for blastocyst implantation (days 4 and 5; Fig. 4). Lif expression is very low to undetectable on day 6 of PSP when blastocyst fails to initiate implantation. These results suggest that Lif is a critical factor contributing to the receptive state of uterus for blastocyst implantation. One explanation of partial rescue by $\mathrm{P}_{4}$ is that other negative factors for receptivity increase in the uterus as time passes. One example is the endocannabinoid signaling, which was previously identified as an important regulator of uterine receptivity for implantation (Das et al. 1995b, Paria et al. 1996, Schmid et al. 1997). The level of anandamide, an endogenous cannabinoid, gradually increases with changing uterine sensitivity from receptive (on day 4) to non-receptive phase (on day 6; Paria et al. 2001). In addition, its level in $\mathrm{LIF}^{-/-}$mice was higher than that of wild-type mice on day 4 of pregnancy (Paria et al. 2001). It will be interesting to investigate whether $P_{4}$ supplementation to non-receptive uterus affects levels of anandamide or not.

Our present study shows that blastocysts can initiate implantation beyond the normal 'window' of uterine receptivity when $\mathrm{P}_{4}$ level is appropriate. However, there is evidence that temporally deferred implantation beyond normal 'window' of uterine receptivity in wildtype mice may accompany various defects in embryo developments leading to embryonic demise before birth (Song et al. 2002, Wang \& Dey 2006). One-day delay of implantation process in $\mathrm{CPLA}_{2}^{-1-}$ mice indeed results in defective postimplantation developments (Song et al. 2002). These results are consistent with increased risk of early pregnancy loss in embryo implantation with sub-optimal uterine receptivity in humans (Wilcox et al. 1999). While our work provides solid evidence that $\mathrm{P}_{4}$ is one crucial factor regulating uterine receptivity, other factors involved in optimizing uterine environment for implantation needs further identification.

\section{Acknowledgements}

The work was supported by NIH grants HD40810 (H L). The authors declare that there is no conflict of interest that would prejudice the impartiality of this scientific work.

\section{References}

Benson GV, Lim H, Paria BC, Satokata I, Dey SK \& Maas RL 1996 Mechanisms of reduced fertility in Hoxa-10 mutant mice: uterine homeosis and loss of maternal Hoxa-10 expression. Development 122 2687-2696. 
Bhatt H, Brunet LJ \& Stewart CL 1991 Uterine expression of leukemia inhibitory factor coincides with the onset of blastocyst implantation. PNAS 88 11408-11412.

Chakraborty I, Das SK \& Dey SK 1995 Differential expression of vascular endothelial growth factor and its receptor mRNAs in the mouse uterus around the time of implantation. Journal of Endocrinology 147 339-352.

Das SK, Wang XN, Paria BC, Damm D, Abraham JA, Klagsbrun M, Andrews GK \& Dey SK 1994 Heparin-binding EGF-like growth factor gene is induced in the mouse uterus temporally by the blastocyst solely at the site of its apposition: a possible ligand for interaction with blastocyst EGF-receptor in implantation. Development 120 1071-1083.

Das SK, Chakraborty I, Paria BC, Wang XN, Plowman G \& Dey SK 1995a Amphiregulin is an implantation-specific and progesterone-regulated gene in the mouse uterus. Molecular Endocrinology 9 691-705.

Das SK, Paria BC, Chakraborty I \& Dey SK 1995 b Cannabinoid ligandreceptor signaling in the mouse uterus. PNAS 92 4332-4336.

Dey SK 1996 Implantation. In Reproductive Endocrinology, Surgery and Technology, pp 421-434. Eds EY Adashi, JA Rock \& Z Rosenwaks. New York: Lippincott-Raven.

Huet H, Andrews GK \& Dey SK 1989 Cell type-specific localization of c-myc protein in the mouse uterus: modulation by steroid hormones and analysis of the periimplantation period. Endocrinology 125 1683-1690.

Lim H, Paria BC, Das SK, Dinchuk JE, Langenbach R, Trzaskos JM \& Dey SK 1997 Multiple female reproductive failures in cyclooxygenase 2-deficient mice. Cell 91 197-208.

Ma WG, Song H, Das SK, Paria BC \& Dey SK 2003 Estrogen is a critical determinant that specifies the duration of the window of uterine receptivity for implantation. PNAS 100 2963-2968.

Murakami M, Nakatani Y, Kuwata H \& Kudo I 2000 Cellular components that functionally interact with signaling phospholipase $\mathrm{A}_{2}$ s. Biochimica et Biophysica Acta 1488 159-166.

Nikas G, Develioglu OH, Toner JP \& Jones HW Jr 1999 Endometrial pinopodes indicate a shift in the window of receptivity in IVF cycles. Human Reproduction 14 787-792.

Paria BC, Huet-Hudson H \& Dey SK 1993 Blastocyst's state of activity determines the 'window' of implantation in the receptive mouse uterus. PNAS 90 10159-10162.

Paria BC, Das SK \& Dey SK 1995 The preimplantation mouse embryo is a target for cannabinoid ligand-receptor signaling. PNAS 92 9460-9464.
Paria BC, Song H, Wang X, Schmid PC, Krebsbach RJ, Schmid HH, Bonner TI, Zimmer A \& Dey SK 2001 Dysregulated cannabinoid signaling disrupts uterine receptivity for embryo implantation. Journal of Biological Chemistry 276 20523-20528.

Psychoyos A 1973 Hormonal control of ovoimplantation. Vitamins and Hormones 31 201-256.

Schmid PC, Paria BC, Krebsbach RJ, Schmid HH \& Dey SK 1997 Changes in anandamide levels in mouse uterus are associated with uterine receptivity for embryo implantation. PNAS 94 4188-4192.

Shen MM \& Leder P 1992 Leukemia inhibitory factor is expressed by the preimplantation uterus and selectively blocks primitive ectoderm formation in vitro. PNAS 89 8240-8244.

Stewart CL, Kaspar P, Brunet LJ, Bhatt H, Gadi I, Kontgen F \& Abbondanzo SJ 1992 Blastocyst implantation depends on maternal expression of leukaemia inhibitory factor. Nature 359 76-79.

Song H, Lim H, Das SK, Paria BC \& Dey SK 2000 Dysregulation of EGF family of growth factors and COX-2 in the uterus during the preattachment and attachment reactions of the blastocyst with the luminal epithelium correlates with implantation failure in LIFdeficient mice. Molecular Endocrinololy 14 1147-1161.

Song H, Lim H, Paria BC, Matsumoto H, Swift LL, Morrow J, Bonventre JV \& Dey SK 2002 Cytosolic phospholipase A2alpha is crucial [correction of A2alpha deficiency is crucial] for 'on-time' embryo implantation that directs subsequent development. Development 129 2879-2889.

Wakuda K, Takakura K, Nakanishi K, Kita N, Shi H, Hirose M \& Noda Y 1999 Embryo-dependent induction of embryo receptivity in the mouse endometrium. Journal of Reproduction and Fertility $\mathbf{1 1 5}$ 315-324.

Wang H \& Dey SK 2006 Roadmap to embryo implantation: clues from mouse models. Nature Review Genetics 7 185-199.

Wilcox AJ, Baird DD \& Weinberg CR 1999 Time of implantation of the conceptus and loss of pregnancy. New England Journal of Medicine 340 1796-1799.

Received 16 November 2006

First decision 30 November 2006

Accepted 4 December 2006 